\title{
Comparison of serum myoglobin and creatine kinase MB isoenzyme in early diagnosis of acute myocardial infarction
}

\author{
ANTHONY P FREEMAN, KEITH R FATCHES, IAN W CARTER, \\ MICHAEL J CLOONAN, DAVID E L WILCKEN
}

From The Departments of Medicine and Microbiology, The Prince Henry Hospital, and the Department of Clinical Chemistry, The Prince of Wales Hospital, Sydney, New South Wales, Australia

SUMMARY We compared the clinical usefulness of serum myoglobin and creatine kinase MB (CK MB) isoenzyme determinations in the early diagnosis of acute myocardial infarction in 109 consecutive patients admitted to a coronary care unit. Of these, 37 patients were diagnosed as having definite infarction, three possible infarction, and 69 no infarction, using World Health Organisation criteria. Blood samples were taken on admission and two to four hours later. Both CK MB and myoglobin were raised in the initial serum samples in 24 of the 37 patients with definite infarction. In an additional seven patients both CK MB and myoglobin were negative in the first specimen though both were detected in the second sample. In five patients $\mathrm{CK} M B$ preceded the appearance of myoglobin while in the remaining patient myoglobin appeared before CK $\mathrm{MB}$.

We conclude that the detection of serum myoglobin does not offer any clinical advantage over CK $\mathrm{MB}$ as an early indicator of myocardial infarction.

Several recent reports have suggested that the estimation of serum myoglobin ${ }^{1-4}$ is as useful for the early confirmation of acute myocardial infarction as the estimation of $\mathrm{CK} M B$ isoenzyme. ${ }^{5-7}$ The aim of this study was to compare the clinical usefulness of myoglobin and $\mathrm{CK} M \mathrm{MB}$ estimations in the early diagnosis of acute myocardial infarction in patients admitted with chest pain to the coronary care unit (CCU).

\section{Methods}

The patients studied were those admitted to the CCU within 14 hours of the onset of acute chest pain. Patients who had received intramuscular injections or suffered other skeletal muscle trauma including defibrillation were excluded, as were patients with chronic renal failure.

Two specimens of blood were collected: one on admission to hospital and a second two to four hours after admission. The serum was separated and a portion frozen $\left(-20^{\circ} \mathrm{C}\right)$ for the myoglobin estimations, while $\mathrm{CK} M B$ and total $\mathrm{CK}$ activity

Received for publication 29 September 1980 measurements were carried out on fresh portions within 24 hours of collection.

Serum myoglobin was measured by an enzyme immunoassay as described previously ${ }^{8}$ in which the normal range was 3 to $65 \mathrm{ng} / \mathrm{ml}$ and a significantly raised level was considered to be $80 \mathrm{ng} / \mathrm{ml}$. The CK MB isoenzyme was separated by electrophoresis on the thin agarose films. After treatment with $\mathrm{CK}$ substrate, the films were examined under ultraviolet light for the presence of $\mathrm{CK} M B$ and scanned using a Corning 720 fluorometer at a wave length of $356 \mathrm{~nm}$. $\mathrm{CK} M B$ was expressed as a percentage of the total $\mathrm{CK}$ activity. The presence of $\mathrm{CK} \mathrm{MB}$ was considered to be significant as normal serum does not contain detectable amounts of CK MB using this procedure. CK MB activity greater than 5 per cent of total creatine kinase activity was interpreted as indicating myocardial necrosis. Total CK activity was measured using Calbiochem $\mathrm{CK}$ reagents which are based on the methods of Rosalki ${ }^{9}$ and the reaction rate was measured on an LC 340 photometer. Total CK activity was raised if greater than $80 \mathrm{U} / 1$.

The diagnosis of acute myocardial infarction was made on the clinical presentation, typical electro- 
Table Presence or absence of raised serum creatine kinase (CK MB) and/or myoglobin (Mb) concentrations on admission and two to four hours later in 37 patients with definite acute myocardial infarction

\begin{tabular}{llll}
\hline & Number of patients & & \\
\cline { 2 - 4 } Blood sample & $\begin{array}{l}\text { CK MB present and } \\
M b \text { present }\end{array}$ & $\begin{array}{l}C K M B \text { present and } \\
M b \text { absent }\end{array}$ & $\begin{array}{l}\text { CK MB absent and } \\
M b \text { present }\end{array}$ \\
\hline Admission & 24 & 5 & 1 \\
Two to four hours after admission & 37 & 0 & 0 \\
\hline
\end{tabular}

Mean time between onset of pain and admission was 5.3 hours (range 1 to 14 hours).

cardiographic changes, and rise in serum enzyme concentrations according to World Health Organization criteria. ${ }^{10}$

\section{Results}

Of the 109 patients in the study, 37 had definite acute myocardial infarction, three had possible infarction, and 69 had no evidence of infarction.

Of the 37 patients with definite acute myocardial infarction (Table) both myoglobin and CK MB were raised in both the initial and second specimen in 24 patients. In five patients $\mathrm{CK} M B$ was raised in the first specimen, with no increase in myoglobin, though both were raised in the second specimen and in one patient increased myoglobin alone was detected in the first specimen. In seven patients the first specimen was negative for both CK $\mathrm{MB}$ and myoglobin, but both were increased in the second specimen. All 37 patients with definite acute myocardial infarction were positive for both $\mathrm{CK} M B$ and myoglobin in the second specimen. The mean time between onset of pain and admission was 5.3 hours (range 1 to 14 hours).

There were three patients with a diagnosis of a possible acute myocardial infarction: one patient with left bundle-branch block had both $\mathrm{CK} M B$ and myoglobin increased in the two specimens; one patient who had chest pain immediately after coronary angiography had an increase of myoglobin only in the first specimen, while both were present in the second; and one patient with suspected subendocardial infarction had no increase of $\mathrm{CK} M B$ or myoglobin in either specimen.

Of the 69 patients considered not to have had acute myocardial infarction, two patients with acute coronary insufficiency had raised myoglobin but no CK MB in both specimens. On admission one of these was intoxicated with alcohol which is known to increase serum myoglobin ${ }^{11}$; no other cause could be found in the second patient. One patient with acute coronary insufficiency had raised $\mathrm{CK} M B$ alone in both specimens. One patient with pericarditis and one with onset of rapid atrial fibrillation had raised $\mathrm{CK} M B$ only. There was no evidence of infarction in the remaining 64 patients, none of whom had raised myoglobin or CK MB.

\section{Discussion}

Serum myoglobin has been shown to increase conspicuously within four hours of acute myocardial infarction ${ }^{12}$ and serum levels increase within two hours in experimentally induced infarction in dogs. ${ }^{13}$ Several authors ${ }^{1-4}$ have suggested that as myoglobin is released earlier than CK MB a serum myoglobin estimation should make confirmation of acute myocardial infarction possible within six hours of the onset of symptoms. In our series 31 of the 37 patients with a diagnosis of definite acute myocardial infarction had increases in both myoglobin and $\mathrm{CK} M B$ at the same time, indicating that both markers are useful early indicators of acute myocardial infarction. In only one of the remaining six patients, however, was increased myoglobin detected before CK MB.

It has been suggested that a single admission myoglobin sample taken within six hours of the onset of symptoms will identify almost all patients with acute myocardial infarction. ${ }^{1-3}$ of the 37 patients, however, $12(32 \%)$ with definite acute myocardial infarction did not have a raised myoglobin on admission and the findings were similar in our earlier report ${ }^{8}$ in which two of eight patients with acute myocardial infarction had normal admission serum myoglobin concentrations. Three recent reports have shown similar results. ${ }^{14-16}$ Thus, confirmation of the diagnosis using this marker would have been missed frequently if this had been based on the analysis of one admission sample only.

Lack of specificity is a further consideration. Of the three patients with a diagnosis of possible acute myocardial infarction, the one who suffered chest pain after coronary angiography had an earlier rise 
in myoglobin. The cardiac catheterisation itself may have been responsible, however, illustrating the problem of interpretation which may occur using this less specific marker of myocardial necrosis. Furthermore, as a non-specific marker of muscle necrosis myoglobin may be increased with trauma, shock, severe renal failure, intoxication with alcohol, and after open heart surgery. ${ }^{11}$

In our study onset of severe chest pain was taken to indicate onset of muscle necrosis, but it is difficult to be certain in the clinical situation of the actual time at which this occurs. Both $\mathrm{CK} M B$ and myoglobin are released from the myocardium with necrosis, but CK MB may be raised as a result of transient ischaemia, with myoglobin remaining within the normal range. ${ }^{17}$ That myoglobin is an index of myocardial necrosis and not of ischaemia is supported by a study in dogs ${ }^{18}$ showing that myoglobin is released from myocardial cells with cellular damage but not after mild reversible injury. This may explain why we found fewer patients with increased serum myoglobin on admission. At that stage in the evolution of the infarct there may have been ischaemia only, with necrosis occurring later. The average time, however, from the onset of pain to admission for those 12 patients without myoglobin present in the first specimen was 4.9 hours which is greater than the appearance time of myoglobin in experimental acute myocardial infarction. It should have been detectable therefore if the onset of pain indicated necrosis. Yet in the present series appearance of $\mathrm{CK} M B$ preceded myoglobin in five patients; and only in one did myoglobin precede CK MB.

In this connection it is interesting that of the 69 patients who on World Health Organisation criteria had no infarction, three nevertheless had a rise in CK MB with normal myoglobin. Acute coronary insufficiency, onset of a rapid arrhythmia, and pericarditis without evidence of infarction were the associated features in these patients. Presumably, leakage of enzymes occurred because of damage to myocardial cells with or without minor necrosis.

In this series, only patients admitted within 14 hours of the onset of symptoms were included in the study. After this time raised myoglobin concentrations could have returned to normal. To detect all patients with myocardial infarction, the biochemical system used must be able to provide diagnostic information over the whole spectrum of admission times. The combined use of $\mathrm{CK} \mathrm{MB}$ and lactate dehydrogenase isoenzyme profiles achieves this by enabling the detection of acute myocardial infarction both early and up to three days after the onset as well as being specific for myocardial injury.

It is clear that there are limitations in the use of myoglobin as a biochemical marker in the diagnosis of acute myocardial infarction. While estimation of CK MB is preferable to total $\mathrm{CK}$, there appears to be no clinical advantage in detecting myoglobin instead of or in parallel with CK MB.

\section{References}

1 Witherspoon LR, Shuler SE, Garcia MM, Zollinger LA. Assessment of serum myoglobin as a marker for acute myocardial infarction. $\mathcal{F} \mathrm{Nucl}$ Med 1979; 20: 115-9.

2 Sonnemaker RE, Daniels DL, Craig WE, Floyd JL, Bode RF. Serum myoglobin determination: laboratory and clinical evaluation. $\mathcal{F}$ Nucl $\mathrm{Med} 1979$; 20: 120-4.

3 Oxley DK, Bolton MR, Shaeffer CW. Myoglobin in myocardial infarction. Am $\mathcal{F}$ Clin Pathol 1979; 72: 137-41.

4 Rosano TG, Sanders LA, Johnson ES, Kenny MA, Clayson KJ, Strandjord P. Myoglobin concentrations and muscle enzyme activities in serum after myocardial infarction and cardiac arrhythmia. Clin Chem 1977; 23: 868-70.

5 Wagner GS, Roe CR, Limbird LE, Rosati RA, Wallace AG. The importance of identification of the myocardial-specific isoenzyme of creatine phosphokinase (MB form) in the diagnosis of acute myocardial infarction. Circulation 1973; 47: 263-9.

6 Blomberg DJ, Kimber WD, Burke MD. Creatinine kinase isoenzymes. Am $\mathfrak{f}$ Med 1975; 59: 464-9.

7 Willerson JT, Stone MJ, Ting $\mathrm{R}$, et al. Radioimmunoassay of creatinine kinase- $B$ isoenzyme in human sera: results in patients with acute myocardial infarction. Proc Natl Acad Sci USA 1977; 74: 1711-5.

8 Cloonan MJ, Bishop GA, Wilton-Smith PD, Carter IW, Allan RM, Wilcken DEL. An enzyme-immunoassay for myoglobin in human serum and urine. Method development, normal values, and application to acute myocardial infarction. Pathology 1979; 11: 689-99.

9 Rosalki SB. An improved procedure for serum creatinine phosphokinase determination. $f$ Lab Clin Med 1967; 69: 696-705.

10 WHO Regional Office for Europe. Report of the 5th working group on ischaemic heart disease registers. Copenhagen: World Health Organization, 1971: 28.

11 Kagen LJ. Myoglobin: biochemical, physiological clinical aspects. New York: Columbia University Press, 1973: 79-116.

12 Stone MJ, Waterman MR, Harimoto $\mathrm{D}$, et al. Serum myoglobin level as diagnostic test in patients with acute myocardial infarction. Br Heart $\mathcal{f} 1977$; 39: 375-80.

13 Willerson JT, Poliner LR, Buja LM, et al. Myoglobinemia as a clue to the presence of acute myocardial infarction (abstract). Clin Res 1976; 24: 422A.

14 Tommaso CL, Salzeider K, Arif M, Klutz W. Serial myoglobin vs. CPK analysis as an indicator of uncomplicated myocardial infarction size and its use 
in assessing early infarct extension. Am Heart $\mathcal{f}$ 1980; 99: 149-54.

15 Gilkeson G, Stone MJ, Waterman M, et al. Detection of myoglobin by radioimmunoassay in human sera: its usefulness and limitations as a emergency room screening test for acute myocardial infarction. $\mathrm{Am}$ Heart $\mathcal{f} 1978$; 95: 70-7.

16 Kampo IS, Fleishaker C, Clain J. An evaluation of serum myoglobin levels as a diagnostic test for myocardial infarction. Lab Med 1980; 11: 33-5.

17 Marmor A, Alpan G, Keidar S, Grenadier E, Palant A. The $M B$ isoenzyme of creatine kinase as an in- dicator of severity of myocardial ischaemia. Lancet 1978; ii: 812-4.

18 Stone MJ, Waterman MR, Poliner LR, Templeton GH, Buja LM, Willerson JT. Myoglobinemia is an early and quantitative index of acute myocardial infarction. Angiology 1978; 29: 386-92.

Requests for reprints to Associate Professor D E L Wilcken, Department of Medicine, The Prince Henry Hospital, Little Bay, New South Wales 2036, Australia. 